СУДОРГИН Олег Анатольевич - доктор политических наук, первый проректор Московского автомобильно-дорожного государственного технического университета (МАДИ) (125319, Россия, 2. Москва, Ленинградский пр-кт, 64; Sudorgin@madi.ru)

МАКАРЕНКО Екатерина Игоревна - кандидат исторических наук, доцент кафедры социологии и управления Московского автомобильно-дорожного государственного технического университета (МАДИ) (125319, Россия, г. Москва, Ленинградский np-кm, 64; Makarenko_madi@mail.ru)

КАРЕЛИНА Екатерина Александровна - кандидат экономических наук, доцент кафедры иностранных языков Московского государственного технологического университета «СТАНКИН» (127055, Россия, г. Москва, Вадковский пер., 1; opferpriesterin@mail.ru)

\title{
ВОЗМОЖНА ЛИ ЭФФЕКТИВНАЯ РЕАЛИЗАЦИЯ ИНТЕЛЛЕКТУАЛЬНОГО РЕСУРСА ТЕХНИЧЕСКОЙ ИНТЕЛЛИГЕНЦИИ В БЛИЖАЙШЕЙ ПЕРСПЕКТИВЕ?
}

\begin{abstract}
Аннотация. Техническая интеллигенция - это кадровая база для обеспечения промышленного производства квалифицированными специалистами, накопившая за многолетнюю историю значительный интеллектуальный ресурс. Авторы статьи считают высшее техническое образование и научную деятельность основаниями для развития данного ресурса и выделяют ряд сложностей в его реализации: отсутствие четкого механизма внедрения инновационных продуктов, неблагоприятный инвестиционный климат, коррупционные составляющие и лоббирование интересов производителей, снижение социальной ответственности и др.

Ключевые слова: техническая интеллигенция, интеллектуальные ресурсы, промышленность, цифровая экономика, научная деятельность, высшее техническое образование
\end{abstract}

B о всех российских политических документах последнего времени постоянно заявляется об острой необходимости перехода экономики страны на новые рельсы технологического развития и цифрового обеспечения производства для подъема благосостояния населения и развития человеческого потенциала. Промышленность, согласно национальной программе «Цифровая экономика РФ», отнесена к приоритетным отраслям экономики, в которых передовые интеллектуальные технологии должны не только формироваться, но активно внедряться, приносить прибыль, повышая производительность труда. Авторы статьи задались целью проанализировать реальную возможность и перспективы решения задач внедрения интеллектуального продукта в промышленности и сопутствующих сферах в ближайшей перспективе.

Мы понимаем, что ситуация с активным внедрением инновационных технологий складывается не совсем благополучно. «Маховик цифры» вращается не так быстро, как того требует развитие экономики и общества в целом. Е.В. Балацкий и Н.А. Екимова на основе анализа Прогноза социально-экономического развития РФ на 2021 год и на плановый период 2022 и 2023 гг. пишут, что «документ консервирует нынешнюю низкотехнологичную структуру российской экономики, говорит об отрицании какого-либо технологического прогресса в ближайшие годы, предусмотренного в иных государственных нормативных актах, в т.ч. и в указе Президента РФ 2018 г. "О национальных целях и стратегических задачах развития Российской Федерации на период до 2024 года"» [Балацкий, Екимова 2021]. Интересное решение проблемы соответствия стратегического планирования и реального внедрения интеллектуально-инновационных продуктов в экономике предлагают Н.И. Никольский, 
Д.А. Рубвальтер и О.В. Руденский. Ученые занимаются разработкой информационной и программно-аналитической системы, «в рамках которой могли бы осуществляться цифровые, тексто-смысловые и композитные оценки функциональных компонентов и показателей проблем политико-стратегических и нормативно-правовых документов» [Никольский, Рубвальтер, Руденский 2020]. Эту систему конкретных показателей авторы называют Системой цифровых стратегий (СЦС). Полагаем, что такой подход в определенной степени не только поможет оценить существующее состояние дел в экономике и промышленности, но и ускорит внедрение интеллектуальных продуктов в реальное производство.

Без соответствующей социальной базы и высококвалифицированных, подготовленных кадров, поддержки занятых в экономике невозможно говорить о перспективах внедрения искусственного интеллекта, инновационных технологий, цифровых платформ. Таким социальным слоем, позволяющим наладить промышленное производство на новых технологических подходах, является техническая интеллигенция.

В широких научных кругах известно, что понятие «интеллигенция» имеет отечественные корни. Оно стало употребляться в России в конце XIX в. для обозначения «мыслящих людей». В середине XX в. в советском обществе к интеллигенции относили людей умственного труда. В настоящее время этот термин сохранился в научной литературе, хотя и является дискуссионным. В масштабном социологическом проекте ученых из РГГУ «Как живешь, интеллигенция?» осуществлен подробный анализ деятельности современной интеллигенции во всех сферах общественной жизни, в т.ч. технической интеллигенции [Как живешь... 2018]. К сожалению, из официальных статистических источников сложно понять, сколько работников можно конкретно отнести к этому социальному слою, однако некоторые данные позволяют считать, что представители технической интеллигенции весомо присутствуют среди всех работников промышленности ${ }^{1}$. В частности, каждый 4-й имеет высшее образование (более $25 \%$ по совокупности работающих), а в таком виде деятельности, как профессиональная, научная и техническая, - каждый 3-й. В этом сегменте учитываются инженеры-проектировщики и другие высококвалифицированные технические кадры [Макаренко 2020]. В отечественном оборонно-промышленном комплексе (ОПК) традиционно сосредоточена элита высококвалифицированных специалистов, и туда в настоящее время направляются значительные средства страны. Такие данные засекречены, но считаем необходимым отметить высокую значимость специалистов ОПК и этого сегмента экономики. Так, в предложенном плане бюджета на 2022 г. расходы по разделу «Национальная оборона» будут выше, чем по разделу «Национальная экономика», и займут вторую строчку после раздела «Социальная политика» 2 .

Говоря об интеллектуальных ресурсах технической интеллигенции как наиболее значимых для создания «умных» машин, цифровых систем и новых технологий, мы исходим из следующего методологического посыла: развитие интеллектуальных ресурсов технической интеллигенции базируется на развитии образования и науки, которые закладывают фундамент для интеллектуализации техники и технологий [Макаренко, Карелина 2020]. Роль высшего

1 Государственный комитет РФ по статистике. Доступ: rosstat.gov.ru; https://digital.gov.ru/ ru/activity/directions/858/ (проверено 20.11.2021).

2 Военный раздел поднимется на второе место в бюджете России по расходам. Доступ: https://www.rbc.ru/economics/03/10/2021/61571a279a79478e0bc0b011?email=tyapinev\%40list. ru (проверено 20.11.2021). 
технического образования, научных разработок и управления в сфере искусственного интеллекта, цифрового функционирования чрезвычайно высока. Какова реальная ситуация с развитием интеллектуального ресурса технической интеллигенции? Являются ли современные условия социально-экономического развития страны достаточными для быстрого и эффективного внедрения перспективных технологий? Обеспечивают ли они научно-технологическую безопасность страны? Что тормозит это развитие?

Выделим основные условия и характеристики развития интеллектуальных ресурсов технической интеллигенции в высокотехнологичном производстве, основываясь на эмпирическом экспертном опросе «Инновационная деятельность технической интеллигенции», проведенном авторами статьи в 2019 г. $(N=51)$. Экспертами выступили ученые в области интеллектуальных систем, руководители предприятий и организаций разных сфер экономики. Многие вопросы носили открытый характер, ответы носили развернутый характер. По окончании полевого этапа опроса из 51 анкеты было только 6, где респонденты не высказали свое дополнительное мнение по различным проблемам, указанным в анкете.

1. Важнейшим направлением реализации интеллектуального потенциала технической интеллигенции являются процессы интеграции в сфере науки, высшего образования и индустрии. Данная проблема задается необходимостью разрешения противоречия между функционированием системы высшего образования, ее научной деятельности, с одной стороны, и внедрением результатов научных разработок в производство, их коммерциализацией - с другой. В результате кодификации ответов на открытый вопрос эксперты на первое место поставили именно проблемы «несогласованности действий».

2. Данные экспертного опроса свидетельствуют, что техническая интеллигенция придает особо важное значение «развитию и распространению информационных технологий». По итогам линейного распределения позиций по вопросу: «Какие направления научно-технической и промышленной политики представляются особо важными для инновационных преобразований в российском обществе?» - первое место респонденты отдали «стимулированию инноваций, внедрению изобретений и новых технологий» (60\%). Наименьшее значение респонденты придают «созданию государственных фондов развития промышленности», а также «созданию венчурных фондов для поддержки стартапов» (по 9,2\%). Промежуточные значения заняли такие ответы, как «развитие системы технического образования» - 31,4\%, «поддержка оборонных предприятий, создание новых видов вооружения» - 22,2\%, «повышение эффективности уже работающих производств» - 22,2\%, «повышение эффективности управления» - 20,3\%, «повышение энергоэффективности» $-14,8 \%$, «разработка космических технологий и коммуникаций» - 20,3\%. Особого внимания заслуживает отношение экспертов к высшему техническому образованию, которое является своеобразным гарантом инновационных преобразований в промышленности и развития интеллектуальных ресурсов технической интеллигенции. В рамках национальной программы «Цифровая экономика РФ» планируется овладение обучающимися всех уровней системы образования ключевыми компетенциями, которые непосредственно связаны с цифровой средой.

3. В октябре 2019 г. президент РФ В.В. Путин подписал указ от 10.10.2019 г. № 490 «О развитии искусственного интеллекта в Российской Федерации» (вместе с Национальной стратегией развития искусственного интеллекта на период до 2030 года). Термин «искусственный интеллект» в Национальной стратегии раскрыт как совокупность технологических решений, позволяющих 
имитировать человеческие когнитивные функции и получать при выполнении различных задач результаты, сопоставимые с результатами интеллектуальной деятельности человека. Искусственный интеллект создается в первую очередь благодаря интеллектуальным возможностям человека, который «заставляет» работать на себя машины. В настоящее время внедрение подобного рода машин осуществляется в первую очередь в Москве, Санкт-Петербурге, крупных городах России. Но во многих регионах страны интеллектуализация производства идет с задержками: не хватает необходимого оборудования и финансовых средств, реальных «долгих» инвестиций.

Может ли в современных условиях техническая интеллигенция активно включиться в процесс инновационного развития отечественного производства на основе искусственного интеллекта? Эксперты в рамках указанного опроса отвечают «да», поскольку именно «умные» системы на основе искусственного интеллекта становятся доминирующим трендом в глобальном развитии, непосредственно влияют на экономики всех стран. Проблема заключается в том, что на данный момент эти системы не являются доминирующими в промышленном производстве нашей страны. Это обстоятельство также подтверждается экспертами: один из них так обозначил реальную ситуацию: «не может быть вообще никакого современного развития без внедрения искусственного интеллекта в региональных заводах, компаниях. Нельзя получить хороший продукт при отсутствии должного цифрового оборудования» (м., 30-40 лет, представитель ОПК).

4. В условиях рыночных отношений, к которым наша страна перешла сравнительно недавно по сравнению с институционализированными экономиками ведущих технологически развитых стран, принципиальным вопросом стало участие бизнеса в программе финансирования инноваций. В России коррупция, лоббизм, уголовное преследование предпринимателей и т.д. не дают возможности быстро и качественно внедрять интеллектуальные системы в производство, управлять ими [Моисеев, Ницевич, Судоргин 2019]. Это является еще одним тормозом эффективной реализации интеллектуального ресурса технической интеллигенции.

5. Все большую актуальность в вопросах реализации интеллектуальных систем в науке и образовании приобретают вопросы управления и систематизации, в т.ч. работа с большими данными (Big Data), метазнание (Metaknowledge). Можно ставить вопрос о формировании нового направления исследований науки на основе больших данных. Необходимо «развивать исследования на основе анализа данных о науке - больших массивов публикаций, патентов, ссылок, грантовых заявок и т.д. Идея использовать метазнание строится на том, что производство научного знания становится все более сложным, появляются новые технологические факторы, которые в том числе влияют на социальные процессы, важные для создания, распространения и использования научного знания» [Губа 2021]. Эксперты в указанном выше опросе также затрагивали эту тему.

6. При разработке искусственных интеллектуальных систем особую значимость приобретает и социальная ответственность. Ученые многих стран и различных направлений в науке бьют тревогу: человек, создавая высокотехнологичные интеллектуальные продукты, перестает понимать, для кого и чего они создаются, теряет управление и контроль над ними. Высшее образование, освоение новых профессиональных навыков и компетенций влияют на осознание социальной значимости деятельности технической интеллигенции. Будущего инженера необходимо готовить не только как узкого специалиста, но и как понимающего социальную сущность принимаемых технических (техно- 
логических) решений. Испанские исследователи М. Кастро и Е. Санкристобал считают, что техническая подготовка должна в обязательном порядке сопровождаться социальным пониманием сущности инженерной деятельности [Castro, Sancristobal 2020]. К сожалению, непонимание основ социальной ответственности более свойственно молодому поколению технической интеллигенции, так называемой когорте сетевого поколения, направленного на интернет-коммуникации [Кожевников 2021]. Представитель производства (ж., 41-50 лет, промышленный сектор экономики) в экспертном опросе так выразила свое мнение об ускорении развития России в ближайшие годы: «...без качественного технического образования, подготовки умных, гуманитарно мыслящих людей невозможно заявлять о развитии страны». Это дает нам право вспомнить о сущностных характеристиках отечественной технической интеллигенции, заложенных еще в конце XIX в.: широкой эрудиции, кругозоре, гуманитарной подготовке и социальной ответственности.

В заключение можно констатировать, что, несмотря на острую потребность экономики страны и ее промышленного сектора в новом интеллектуальном продукте, темпы его внедрения замедляются. Это связано с рядом сложностей в формировании интеллектуального ресурса технической интеллигенции, которая является социальной и кадровой базой технологических преобразований в промышленности; со слабым внедрением инновационных продуктов на цифровой платформе; с отставанием от ведущих стран-лидеров в интеллектуализации производства; коррупцией; сложностями с инвестициями в реальное производство. Необходимо обратить внимание на высшую техническую школу, задача которой состоит в том, чтобы не только заложить профессиональные качества специалиста, но и сформировать социальную ответственность у будущих представителей технической интеллигенции.

\section{Список литературы}

Балацкий Е.В., Екимова Н.А. 2021 Будущее российской экономики глазами властей. - Власть. Т. 29. № 1. С. 9-15.

Губа К.С. 2021. Большие данные в исследовании науки: новое исследовательское поле. - Социс. Социологические исследования. № 6. С. 24-33.

Как живешь, интеллигениия? Социологические очерки: коллективная монография (отв. ред. Ж.Т. Тощенко). 2018. М.: Центр социального прогнозирования и маркетинга. $360 \mathrm{c.}$

Кожевников А.М. 2021. Интернет-коммуникационные факторы ценностных ориентаций российской молодежи. - Власть. Т. 29. № 4. С. 54-60.

Макаренко Е.И. 2020. Факторы трудовой деятельности современной российской технической интеллигенции. - Регионология. Т. 28. № 2. С. 322-349.

Макаренко Е.И., Карелина Е.А. 2020. Ресурсный подход к современной технической интеллигенции. - Социология. № 2. С. 143-152.

Моисеев В.В., Ницевич В.Ф., Судоргин О.А. 2019. Взаимодействие власти и бизнеса в России. - Управление. Т. 7. № 1. С. 77-85.

Никольский Н.И., Рубвальтер Д.А., Руденский О.В. 2020. Разработка информационной и программно-аналитической системы «Цифровые стратегии» Российской Федерации (І этап). - Власть. Т. 28. № 6. С. 103-109.

Castro M., Sancristobal E. 2020. From Technology Enhanced Learning to Ethics and Critical Thinking as Part of the Engineering Education: Skill Driven with Humanities Comprehension Editorial. - International Journal of Engineering Pedagogy. Vol. 10. Is. 1. P. 4-6. 
SUDORGIN Oleg Anatol'evich, Dr.Sci. (Pol.Sci.), First Vice-Rector of Moscow Automobile and Road Construction State Technical University (MADI) (64 Leningradsky Ave, Moscow, Russia, 125319; Sudorgin@madi.ru)

MAKARENKO Ekaterina Igorevna, Cand.Sci. (Hist.), Associate Professor of the Chair of Sociology and Management, Moscow Automobile and Road Construction State Technical University (MADI) (64 Leningradsky Ave, Moscow, Russia, 125319; Makarenko_madi @ mail.ru)

KARELINA Ekaterina Aleksandrovna, Cand.Sci. (Econ.), Associate Professor of the Chair of Foreign Languages, Moscow State University of Technology «STANKIN» (bld. 1, 3a Vadkovsky Lane, Moscow, Russia, 127994; opferpriesterin@ mail.ru)

\section{IS IT POSSIBLE TO REALIZE THE INTELLECTUAL RESOURCE OF THE TECHNICAL INTELLIGENTSIA IN THE NEAR FUTURE?}

\footnotetext{
Abstract. Technical intelligentsia is a personnel base for providing industrial production with qualified specialists, which has accumulated a significant intellectual resource over the years. The authors of the article consider higher technical education and scientific activity to be the basis for the development of this resource and highlight a number of difficulties in its implementation, such as the lack of a clear mechanism for introducing innovative products, an unfavorable investment climate, corruption components and lobbying for the interests of manufacturers, reducing social responsibility, etc. Keywords: technical intelligentsia, intellectual resources, industry, digital economy, scientific activity, higher technical education
} 